\title{
Tolerance and inclusive competence as the main components of an inclusive culture
}

\author{
Tatyana Lisovskaya ${ }^{1}$, and Tatyana Zhuk $^{2 *}$ \\ ${ }^{1}$ The Academy of Management under the President of the Republic of Belarus, Belarus \\ ${ }^{2}$ Brest Regional Center of correctional and educational training and rehabilitation, Belarus
}

\begin{abstract}
The article raises the problems of the formation of an inclusive culture of teachers working with intellectually disabled children in centers of social and professional rehabilitation for the people with special psychophysical development needs (hereinafter referred to as the SPDN). Two components of an inclusive culture are presented: tolerance and inclusive competence. The mechanism of professional and social rehabilitation of people with intellectual disabilities is shown on the example of Brest region of the Republic of Belarus.
\end{abstract}

The main trend in the development of the modern the world is the recognition and inclusion into the society of all citizens, regardless their race and gender, religious beliefs, cultural and ethnic characteristics, social origin, particular physical, mental development, etc. Such recognition can only be achieved in a society with a high level of inclusive culture.

In 2016, the Republic of Belarus (along with 124 countries of the world) ratified the UN Convention on the Rights of Persons with Disabilities. This international document activates the states having signed the Convention to ensure people with disabilities enjoy all human and civil rights to live in an open and civilized society.

Inclusive values of education define a new paradigm of an educational relationship and orient its participants towards the principles of humanism and equality.

Article 2 of the Code of the Republic of Belarus on Education defines one of the principles of state policy in the field of education - this is a guarantee of the constitutional right of everyone to education and ensuring equal access to education [1].

In Belarus, the transition to inclusive education has begun through the implementation of the "State Program for the Development of Special Education in the Republic of Belarus for 2012-2016". In accordance with this program, special education should become adequate and comparable with international standards applicable to persons with SPDN. New tasks of socio-economic development of the Republic of Belarus require further development of the system of special education on different levels, taking into account the specific national conditions, the potential in the development of special pedagogy and psychology in Belarus, foreign experience in the field of inclusive approaches to education [2].

The main goals of the current State program "Education and Youth Policy" for 20162020 are "improving the quality and accessibility of education in accordance with the needs

\footnotetext{
* Corresponding author: zhuk tatsiana@mail.ru
} 
of the innovative economy, the requirements of the information society, the educational needs of citizens, developing the potential of young people and their involvement in socially useful activities" [3].

The normative document giving the most complete understanding of the principles, goals, objectives and mechanisms for the development of inclusive education in our country is the Concept for the Development of Inclusive Education of Persons with SPDN in the Republic of Belarus [4].

Building an inclusive educational space is impossible without building a so called "foundation of values" An inclusive culture serves as such a foundation. This phenomenon is considered in the works of such researchers and scholars as T. Booth, M. Einsko (2007), S.V. Alekhina (2011), V.V. Khitryuk (2012) and others, and is interpreted as 1) a special philosophy according to which values, knowledge about inclusive education and responsibility are accepted and shared between all the participants of this process; 2) a part of the general school culture aimed at promoting the values of inclusion, which helps to increase the efficiency of the inclusive process as a whole; 3) a unique microclimate of trust, contributing to the development of relevant relations between the family and the school, avoiding conflicts between the participants of the process; 4) a special inclusive atmosphere, in which the implemented modifications are adapted to the needs of a particular school and organically woven into its general structure, and teachers are given the opportunity to receive various support, both from the administration and from other teachers, to reduce the risk of many contradictions ; 5) the fundamental basis for creating the inclusive society culture, where the diversity of needs is welcomed, supported, accumulated by society, providing the opportunity to achieve high results in accordance with the goals of inclusive education and ensuring the preservation, acceptance, cooperation and stimulation of continuous improvement of the pedagogical community and the society as a whole " [5]

The formation of an inclusive culture in educational institutions and organizations is considered by researchers (M.A. Kolokoltseva, N.V. Starovoit and others) as a task the solution of which lies on the basis of inclusion and comprises the adoption of values of diversity, tolerance for differences, cooperation encouraging everyone's achievements and creating an inclusive community based on them.

We can consider tolerance towards children with disabilities as part of an inclusive culture. Scientific and structural-substantive aspects of the formation of tolerance towards children with disabilities were developed and presented in the works of Russian and Belarusian scientists: V. A. Badil, S. L. Bratchenko, A. N. Konopleva, I. V. Kovalets, E. A. Lemekh, T. L. Leshchinskaya, M. L. Lyubimov, A.R. Maller and others.

The concept of tolerance is ambiguous and diverse. Each culture has its own definitions of tolerance, which are largely similar and for the most part indicate willingness and ability to perceive a person or thing without protest, respect the freedom of another, allow, admit, show generosity, patience, endurance, readiness for reconciliation, ability to accept another person. A variety of approaches to understanding tolerance show that it is regarded as an important social value, the norm of social life, the principle of human relationships and behavior, and personal quality. Tolerance is basically focused on the main requirement - the recognition of another person as equal to oneself. As an international principle, it takes the form of the expression "We are all different, but all equal."

The work in the conditions of inclusive education is impossible without the formed inclusive competency, which requires the teacher to possess special knowledge, skills and abilities, as well as the ability to analyze his own activities, with the aim of the most effective implementation of the educational process in the conditions of joint training of children with different educational needs. 
I. A. Turchenko defines inclusive competency as the structure of components: motivational-value component - is expressed in the teacher's intention to carry out pedagogical activities on the principles of inclusion; cognitive component - consists in teacher's possession a combination of theoretical and methodological knowledge about the specifics of teaching children with SPDN; activity component- presumes application of practical skills necessary for the successful training and education of students in the context of inclusion, and the experience of professional activity; reflective component implies the teacher's ability to analyze his own professional pedagogical activity and its results, to adjust pedagogical activity in the conditions of inclusive education [6].

Thus, the expansion of professional competencies of teachers working in vocational education institutions with intellectually disabled adolescents is an essential condition for the formation of an inclusive culture of both the teacher and the institution as a whole.

Annually in the Republic of Belarus the number of children under the age of 18 with peculiarities in psychophysical development is increasing on average by 5-6 thousand and makes up on average $6-8 \%$ of the total number of children

According to the Republican database on children with SPDN, in the academic year 2018/2019 the nosological group of children with mild intellectual disability made up 7123 people under18, 1189 of them received working professions in vocational education institutions with 39 specializations and qualifications.

In the Brest region, such students have had the opportunity to train for working professions since 1993. Vocational educational institutions (hereinafter - VEI) provide various forms of organization of the educational process: special groups, joint training groups (integrated), at home. However, in order to accumulate resources and taking into account the accumulated experience, on the basis of the VEI, as structural units, centers of vocational and social rehabilitation began to open for people with SPDN. As an example we present the work of the educational institution "Ivatsevichi State Vocational Lyceum of Agricultural Production" (Brest region), where such a center was opened in 2008. In the center, the correctional and rehabilitation process is carried out in accordance with individual student rehabilitation programs; professional adaptation of students and their further integration into the society; individual training is organized (if necessary); the system for monitoring the employment and professional adaptation of the graduates has been created.

In the 2008/2009 academic year, 54 students with intellectual disabilities were trained at the center in integrated qualifications such as a gardener, vegetable grower, seamstress, an agricultural machinery mechanic, a bricklayer. In the 2009/2010 academic year additional professions were introduced: a plasterer, a construction painter. In the 2011/2012 academic year, 104 students studied, 9 study groups were formed.

Every year, the list of professions was expanded, some professions were integrated in order to give the graduate the opportunity to get several professions and a broader choice of jobs for the qualifications received. By the academic year 2018/2019, the center offered such new professions and integrations as a machine milking operator, a seamstress, a vegetable breeder, a painter, an embroiderer, a gardener, an agricultural machinery locksmith, a plasterer, a tiler . Over the years of operating the center has trained 277 young workers.

The organization of the educational process for people with intellectual disabilities includes:

- general educational component (mathematics, the basics of law, physical education and health, protection of the population and territories from emergency situations);

- professional component, which consists of a general professional cycle (fundamentals of economics, electrical engineering, Belarusian language (professional vocabulary), 
applied informatics, drawing, labor protection, psychology and ethics of business relations) and a special cycle;

- educational subjects of mandatory choice (social orientation and traffic rules for pedestrians).

Both components are substantively interconnected and aimed at achieving the main goal - preparing a graduate with intellectual disability for social interaction and professional activity. For example, the contents of the curriculum in mathematics for the 11th -12 th grade include such tasks as: determining the length of the working day, holidays, calculating time from home to work, using the urban transport schedule on the Internet, solving calculation problems using the concepts of "area "," perimeter "" volume ": wallpapering, painting, whitewashing of the walls, floors, ceilings, determining the consumption of building materials for repairing an apartment, building a house, greenhouse, etc.

In 2018 the publishing house "Narodnaya Asveta" first published the textbook "Mathematics" by the authors T.V Lisovskaya, M.E. Skivitskaya and M.I. Voitkevich for the XIth grage of advanced social vocational training of students with mild intellectual disability [7]. All its contents are aimed at realizing the main goal - vocational and labor training of students with intellectual disabilities. The pages of this textbook use new information and communication technologies, in particular augmented reality, which, combined with the text of the book, helps to expand the spatial scope of the figurative perception of special students and can be used as an aid to visualizing educational material by making the information presented on the pages of the textbook, interactive. Close interdisciplinary connections inherent in the content of teaching mathematics allows to use the augmented reality technology in the aspect of career guidance which expands the ideas of future graduates about the professions available to them, as well as their opportunities and conditions for receiving them.

The professional skill contests play a significant role in ensuring successful professional training of persons with SPDN. These students have a lot of difficulties in adaptation to new conditions and activities. The professional skills contests help facilitate future social and labor adaptation, make the first steps into the profession, acquire work skills in a production environment, and feel competitive and independent.

The main step to adaptation for the job is made by getting a practical training, which is the final stage in consolidating and improving the professional skills of students, as the conditions of training are as close as possible to the conditions of the future job.

The preparation period is important. The requirements of labor protection, fire safety and electrical safety at workplaces, the peculiarities of the organization of the technological process, internal labor schedule are studied in detail. The content of the preparatory period also includes the preliminary work of the master of industrial training with the employees who are in direct contact with students with intellectual disabilities. On this stage, it is important to conduct explanatory work with the employer correctly: to explain the psychophysical peculiarities of the graduates in order to prevent presenting requirements inadequate to their capabilities. Unfortunately the problems arise after the graduate of the center starts working. Some business leaders don't understand the behaviors of these young people. Lack of self-control, suggestibility, weak will, and other peculiarities of the graduates lead to conflicts, misunderstanding, as a result of which they many lose their jobs.

The final stage of the center's work is the patronage of its graduates two years after the graduation. The specialists of the center monitor the difficulties and problems arising in the independent living of the graduates and give them timely assistance and support.

Thus, the main idea of the implementation of inclusive education in the professional lyceum is the organization of affordable vocational education for students with intellectual 
disabilities, the use of adaptive technologies for their education. High-quality professional education, the employment of students with SPDN are not only their ticket to life, social guarantees and a sense of confidence in the future, but also a successful socialization, ensuring a tolerant attitude of the society to them.

Since the establishment of the center of professional and social rehabilitation for people with disabilities the specialists of the Brest Regional Center of Correctional-Developing Education and Rehabilitation " (hereinafter referred to as RCCDE\&R) have been constantly providing psychological and pedagogical support to the teachers of the lyceum, consisting in the formation of their professionally-inclusive competence. Since the administration and teachers of the Lyceum have been enough experienced working with intellectually disabled children and a tolerant attitude towards them has been formed, the motivation and value component based on the inclusive principles of pedagogical activity has already been generated in this institution. To a greater extent the educational seminars and trainings were aimed at the formation of a cognitive component: theoretical information about psychological and pedagogical characteristics of children with intellectual disabilities, the knowledge of psychophysical characteristics of this nosological group, their cognitive and emotional-volitional sphere, the ability to diagnose their educational opportunities and to organize their training.

The activity component has been generated and improved both in the the educational process itself within the lyceum in the form of open lessons, methodological associations, advanced training and by holding regional seminars, professional skill competitions, and the international conference of special education teachers on the basis of the Lyceum in 2011.

We paid less attention to the development of the reflective component of inclusive competence. At this stage, we see that this is not only the ability of teachers to analyze their professional pedagogical activity and its results, to adjust it to the conditions of the inclusive education, but also to prevent emotional burnout.

In January 2019 the specialists of RCCDE\&R held a training seminar in the Lyceum on the formation of an inclusive culture. 37 specialists including teachers, masters of professional training and educators took part in the seminar. The participants were asked to fill in an express questionnaire "Tolerance Index" by G.U. Soldatova, OA Kravtsova, OE Khukhlaev, L.A. Shaigerova. In this questionnaire three subscales are aimed at diagnosing such aspects of tolerance as ethnic tolerance, social tolerance and tolerance as a personality trait. The result of processing the forms showed that no participants showed a high level of tolerance, 30 people showed an average level of tolerance and 7 people had a low level of tolerance.

According to the subscale "Ethnic Tolerance", which reveals a person's attitude to representatives of other ethnic groups and attitudes in the field of intercultural interaction, 10 people showed a low level of tolerance and 27 people showed an average level of tolerance.

According to the subscale "Social Tolerance" which allows to study tolerant and intolerant manifestations in relation to various social groups as well as to study personality attitudes towards certain social processes, 9 teachers showed a low level, 26 - an average and 2 - a high level of tolerance.

The subscale "Tolerance as a personality trait" revealed 7 people with a low level and 30 people with an average level of tolerance. In this case the result reveals personality traits, attitudes and beliefs that largely determine a person's attitude to the world.

The test result allows us to conclude that most teachers combine both tolerant and intolerant traits, which generally affects the formation of an inclusive culture of the participants in the educational process. 
In addition, it can be assumed that the long-term work of a teacher working with intellectually disabled children leads to professional burnout.

We have to admit the fact that over the years the teachers have a gap in theoretical knowledge about the characteristics of the cognitive and emotional-volitional sphere of intellectually disabled students, as well as in the ability to diagnose the learning opportunities of these students. This is mostly manifested among the masters of professional training when they try to compare the concepts of "labor preparation" of a student and the diagnosis of "intellectual disability". Working simultaneously with two groups of children: standard-typed and those with SPDN, the masters see that in most cases children with intellectual disabilities are better trained in labor than their norm-typed peers. However, the curriculum of the 1st department of the auxiliary school includes 6 hours of labor training in the conditions of integrated education and 10 hours in the conditions of the auxiliary boarding school, and students with intellectual disabilities pass the final exam for the basic education course only in the subject of "Labor Training". According to the school curriculum standard-typed students have only 1 hour of labor training per week. Therefore, in this case it is also appropriate to talk about the inclusive competence of the teacher.

At the present stage of development of the society, the issue of creating an inclusive society has taken the priority in the Republic of Belarus. The formation of an inclusive culture often begins with participants in the educational process and other subjects involved in the education of children with disabilities. In our opinion, an inclusive culture involves creating a welcoming atmosphere, overcoming environmental barriers and negative public outlooks. Today the model of the formation of an inclusive culture is developing as a complex multilevel and multicomponent phenomenon. It is constantly being filled with content. To receive scientifically based, reasoned answers to the questions arisen, serious researches are required.

\section{References}

1. Education Code of the Republic of Belarus: adopted by the House of Representatives of the National Assembly of the Republic of Belarus (Minsk, 2011)

2. State program for the development of special education in the Republic of Belarus for 2012-2016: Resolution of the Council of Ministers Belarus, 3, 3-17 (Minsk, 2012)

3. On approval of the State program "Education and youth policy" for 2016-2020 (Minsk, 2016)

4. The concept of development of inclusive education for people with disabilities in the Republic of Belarus (Minsk, 2015)

5. G.Yu. Kozlovskaya, N.A. Palieva, N.M. Borozinets, Scientific journal, 52, 125-131 (2016)

6. I. A. Turchenko, Abstract of dissertation for the degree of candidate of pedagogical sciences, (Minsk, 2018)

7. T. V. Lisovskaya, M.E. Skivitskaya, M.I. Voitkevich, Mathematics: a textbook for the 11th grade of the first branch of the auxiliary schools from Russian language learning (Minsk, 2018) 